\title{
제60차 유엔총회 제2위원회 일반토의
}

\section{I . 제 2위원회 일반토의(1)}

10.3(월) 개회된 유엔총회 제2위원회에서는 Ocampo 사무차장의 보고에 이어 9월 정상회의에 대 한 평가 및 향후 이행방안 등에 대한 일반토론이 진행 되어 G- $77, \mathrm{EU}$ 등 회원국 대표의 기조연설을 청취한 바, 10.3(월) 4(화)간의 주요 발언내용 아래와 같음.

\section{1 핵심사항}

$\square$ 대부분의 국가는 지난 9월 정상회의 결과에 대해 긍정적으로 평가하면서 앞으로의 과제는 정상 합의 사항을 효율적으로 이행하는 것임을 강조함.

- 고채무최빈개도국(HIPC)에 대한 부채탕감, $\mathrm{ODA}$ 증가 약속 등 개도국의 경제발전을 지원 하기 위한 국제사회의 노력에 대해서도 긍정적 으로 평가.

$\square$ 또한 MDGs와 관련, 일부 개도국, 특히 아프리카 국가가 여전히 어려움에 처해 있고, 특히 금년의
경제성장률이 전년도보다 낮을 것으로 생각되며 최근의 고유가와 자연재해, 인플레이션 상승 압력 등으로 거시경제적 측면에서 어려움이 클 것으로 예상하는 국가가 많았음.

$\square$ 지속가능 발전과 관련 대부분의 국가는 9월 정상 회의가 향후 환경이슈 논의에 방향을 제공하고 있 다고 하면서 JPOI의 이행, 기후변화 문제에 대한 즉각적 대처 등을 주장함.

$\square$ G- 77을 비롯한 개도국은 도하라운드 및 WTO 등 국제무역 정책 및 규범과 관련하여 개도국에 대한 특별 고려가 미흡함을 지적하고, LDCs, LLDCs 및 SIDS 국가에 대한 국제사회의 특별한 지원과 기 합의 프로그램(브뤼셀행동계획, 알마티행동계 획 및 모리셔스전략)의 충실한 이행을 촉구함.

- 또한 중간소득국가의 외채에 대한 탕감도 중요 함을 강조함.

$\square \mathrm{EU}$ 는 금년 정상회의를 포함한 국제사회의 노력, 특 히 기후변화를 포함한 환경분야의 중요성 및 시급 
성 인정을 높이 평가하면서, 2위원회가 의제 및 일 반토론 축소를 통해 특정의제에 대한 집중 논의, 상 호 토의 활성화 등을 통해 성과를 제고함을 주장함.

\section{2. 주요 발언 요지}

가. Ocampo사무차장

$\square$ 금번 정상회의는 개도국들이 자신들의 포괄적인 국가개발전략 마련에 합의하고, 선진국은 ODA 를 2010년까지 1300억불로 증액하고, 최근 브레튼우 즈 기구가 HIPC에 대한 부채 탕감에 합의하는 등 개발에 관한 ownership, 원조, 부채탕감이라는 3 가지 분야에 있어서 중요한 공약을 촉진하는 계기 가 되었음.

$\square$ 그럼에도 불구하고 무역 협상, 여타 빈국 및 중소 득 국가들의 부채, 국제경제정책 결정과정에서의 개도국의 소외 문제 해결을 위한 보다 구체적인 조치가 필요함.

$\square 2005$ 및 2006년도 세계 경제성장이 3\%대에 머물 것으로 기대되는 등 세계 경제의 하강이 우려되는 가운데 원유 가격 상승은 원유 수입 개도국들의 경제발전에 또 다른 우려를 초래하고 있음

$\square$ 그럼에도 불구하고 그간 국제무역은 지속적으로 성장하고 있으며, 국제금융시장은 일반적으로 안 정되어 있고 많은 개도국들의 무역수지는 상당히 개선되고 있음. 많은 개도국들의 최근 경제 상태 에 비추어 볼 때 바람직한 국내 및 세계 경제 상황 하에서 실질적인 성장이 가능함을 보여주고 있음.

- 세계경제 하강의 주요 원인이 되고 있는 세계 경 제의 불균형을 해소해 나가는 것이 향후 장기적
개발아젠다 달성을 위한 주요한 부분으로 보임.

$\square$ 빈곤 근절을 위한 10 년간 유엔계획 이행에 관한 사무총장의 보고서는 빈곤근절을 위한 중심적 요 소로 고용에 초점을 맞추고 있으며, 내년도 총회 는 빈곤 근절을 중심적 목표중 하나로 하고 있는 브뤼셀 행동계획의 5년간 성과 검토를 위한 특별 회기를 개최할 예정임.

$\square$ 세계화의 중요한 요소가 되고 있는 국제이민에서 고학력자와 숙련된 노동자의 해외 이민은 소위 “ brain drain”과 이로 인한 이민국의 경제적 잠재 력의 손실을 초래할 수 있음. 그럼에도 불구하고 국제이민은 이민국과 피이민국 모두에게 혜택을 줄 수 있는 바, 한 해 국제 송금은 1,300 억불에 달 하며 이중 $60 \%$ 는 개도국으로 들어가고 있음.

- 금주 국제이민위원회의 보고서가 사무총장에게 제출될 예정이며, 총회는 내년도 국제이민과 개 발에 관한 고위급 대화를 개최할 예정임.

\section{나. G- 77(자메이카)}

$\square$ 금번 정상회의를 통해 많은 MDGs 달성이 합의된 시간내에 달성되기 어렵다는 것이 확인되었으나, 이를 계기로 몇몇 선진국들이 2015년 0.7\% ODA 목표 달성을 위한 시간 계획 제시, 18 개 HIPC국가 에 대한 부채 탕감 및 여타 빈국 및 중간소득 개도 국의 부채 해소 의지 표명, 새로운 개발 재원에 관 한 pilot project 개시 등 MDGs 달성을 위한 긍정 적인 조치들이 취해지게 된 것을 기쁘게 생각함.

$\square$ 이러한 긍정적인 진전에도 불구하고 무역, 재정, 기술 및 세계경제 거버넌스 등 구조적인 문제에 
대한 진전은 미미함.

- 금번 정상회의는 WTO 홍콩 각료회의에 대해 강하고 분명한 메시지를 주지 못하였으며, 브 레튼우즈 기구와 WTO는 재정, 무역, 국제금융 체제 개혁 등 국제 정책의 토의 및 협조에 관한 공식적인 협의체를 만드는 것에 계속 반대해 오고 있음.

- 선진국의 무역보조금 폐지, 개도국 재화 및 서 비스의 선진국 진입 용이화, 기술이전을 촉진할 수 있도록 하는 지적재산권 관련 규정 제정 등 은 개도국이 일관되게 요청하고 있는 사항임.

$\square$ 개발에 관한 주요 책임이 해당국에 있는 것과 함 께 개도국이 자신의 개발정책을 결정할 수 있는 정책 공간(policy space)을 가져야 함.

기배발재원 국제회의" 후속조치에 대한 검토를 위 해 카타르의 2007년 회의 유치 제안을 지지하며 금년 총회에서 이를 결정할 수 있기를 촉구함.

$\square$ 해외송금 비용 감소 등 이민관련 사항에 대한 국 제사회의 논의가 필요하며, 이와 관련 페루가 제 안한 2006년 4월의‘ 이민에 관한 국제회의"에 기 대가 많음.

$\square 77$ 그룹은 JPOI 등을 충실히 이행할 것이며, 이와 관련 지난 13 차 CSD에서 합의한 사항의 충실한 이행이 관건이라고 생각하며, 14 차 CSD의 주제인 “ 에너지, 산업발전, 오염 및 기후변화”는 국제사회 의 진전된 협력을 필요로 하는 특별한 분야로서 중요성을 갖고 있음.
다. EU(영국)

$\square$ 금년은 9월 정상회의 등을 통해 MDGs 달성을 위 한 국제협력을 강화하기로 합의한 의미있는 한 해 가 되고 있으며, 관건은 이러한 약속을 실질적으 로 이행해야 하는 것임.

- 개도국은 빈곤퇴치, 지속가능발전 등 MDGs 달 성을 위한 국가개발전략을 채택해야 하며, 선진 국 및 UN은 개도국의 노력을 지원하기 위해 개 발원조 확대, 부채탕감 및 무역구조 개혁 등을 추진해야 함.

$\square \mathrm{EU}$ 는 2015년까지 GNI 대비 0.7\%의 ODA 달성 시간표를 작성하였으며, 무역문제와 관련 홍콩 각 료회의에 많은 기대를 갖고 있음.

$\square$ 금년에 중요한 합의가 이뤄진 분야는 지속가능 발 전 및 환경분야인 바, 특히 9월 정상회의에서는 기 후변화에 대한 국제적 노력의 시급성과 중요성에 관하여 결론을 내렸음.

- 이와 관련 금년 몬트리올 당사국 총회시 장기적 기후변화 대응 조치(long- term measures)를 위한 협상방안이 마련되기를 기대함.

$\square 2$ 위 운영방안과 관련 일반 토론을 줄이는 대신 상 호토의 확대, 각 그룹간 회의 활성화, 의제수 감축 및 특정 의제 집중논의 등이 중요하다는 생각을 견지하고 있음.

라. 남아프리카캐발연합(나미비아)

$\square$ 사하라 이남 아프리카 국가(SADC)는 AIDS로 인 한 사망자가 동 지역에서만 백만명 이상이며, 인 구의 $38 \%$ 가 빈곤선 이하의 삶을 유지하고 있는 
등 MDGs 달성이 어려운 바, 국제사회의 지원, 특 히 외채탕감이 시급함.

- SADC의 외채는 총 781 억불에 달하며 연간 68 억 불을 외채 상환에 사용하고 있는 바, 이는 MDGs 달성에 사용되는 금액보다 더 많은 금액임.

- 최근 HIPC에 대한 선진국의 외채탕감을 환영하 나, 비 HIPC 국가도 외채상환 능력의 한계를 넘 고 있으므로 이러한 비 HIPC 국가의 외채부담을 경감하는 조치를 국제사회가 강구하기를 희망함.

$\square \mathrm{SADC}$ 는 공적개발원조를 절실히 필요로 하고 있으며, 또한 홍콩 각료회의에서 개도국의 입장 을 반영하여 도하개발라운드를 완성할 수 있기 를 희망함.

마. 아세안(인도네시아)

$\square$ 아세안국가는 지속적 발전을 통해서만 MDGs가 달성될 수 있다는 관점을 보유하고 있으며, 아세 안 연합(ASEAN Community)의 실현 및 금명간 의 아세안 헌정(ASEAN Charter)의 제정은 역내 국가의 발전, 안정 및 평화 구축에 기여할 것으로 희망함.

$\square$ 아세안국가는 국제파트너십 형성만이 지속발전을 담보하며, 이를 위해 개발재원의 확보, 특히 개발 재원 국제회의 후속회의가 중요하다고 판단함.

또한 ODA 증가 시간표 작성 및 원조의 질과 효과 성 제고, 중간소득국가의 부채 탕감, WTO 및 브 레튼우즈체제에 대한 개도국 참여 및 입장 반영확 대, 자연재해(쓰나미) 조기 경보체제 구축 및 피해 국가에 대한 지원 확대, 에너지가격 상승에 대한
대응이 중요함.

바. 기타

일본은 최근의 고유가가 재원동원에 장애가 됨을 지적하면서 동 문제에 대해 2위원회에서 심도있는 논의를 희망하고, 또한 최근의 조류독감 및 SARS 확산 방지를 위한 국제사회의 노력을 촉구함.

$\square$ 몽고, 짐바브웨, 스리랑카, 파라과이, 타지키스탄 등은 내륙최빈개도국(LLDC)에 대한 특별한 고려 및 알마티행동계획의 이행을 촉구하였으며, 또한 WTO 도하라운드 협상시 개도국의 입장 반영, HIPC 뿐만 아니라 모든 개도국의 부채탕감 등을 주장함.

$\square$ SIDS를 대표한 모리셔스는 최근의 고유가가 개도 국에 특히 심대한 영항을 미침을 주장하면서 대체 연료(사탕수수 등을 이용한 바이오 연료, 해열을 이용한 발전)의 사용 확대, 기술이전, 기후변화로 인한 허리케인 등 자연재해 증가 및 이에 대한 국 제사회의 노력을 촉구함.

$\square$ 파라과이, 스리랑카 등은 이민 및 국제송금 비용 인하를 주장하면서, 교육 등의 투자를 위한 개발 원조 증액을 촉구함.

3. 쿠바 경제제재에 대한 쿠바, 미국간 논쟁

$\square$ 일반토론중 쿠바는 현재 자국의 어려움은 여러 외 적인 요소에 기인하는데 특히 40여년전 미국 정부 에 의해 부여된 불합리하며, 비합법적인 경제 및 통상, 재무 제재조치가 주요 요인이라고 언급함.

- 또한 미국은 경제 사회 분야의 발전을 추진하고 
있는 쿠바의 노력을 무시하고 있으며, UN총회

는 선진국에 의한 개도국 제재(blockade)를 없 애려고 노력해야 함을 주장함.

$\square$ 이에 대해 미국은 반박권을 신청하여 쿠바에 대한 무역제재는 쌍방간에 논의가 이뤄져야 하는 문제 로서 미국은 현재 쿠바에 가장 많은 원조를 제공 하는 국가이며, 쿠바의 불안정한 경제 및 정치상 황은 독재정부에 그 원인이 있다고 주장함.

\section{II . 제2위원회 일반토의(2)}

10. 5 (수) 개최된 2 위원회 일반토의에서 신각수 차 석대사는 2009년까지 우리의 ODA 배증 계획, APCICT 설립, 유엔 거버넌스 센터 설립 예정, IVI 사업 지원 등에 대해 아래 요지로 발언함.

\section{1 우리나라 발언요지}

$\square$ 금번 정상회의 결과 문서에 포함되어 있듯이 세계 정상들이 MDGs를 포함한 포괄적이고 행동지향 적인 아젠다에 대한 공약을 새로이 한 것에 유의 함. 이제 구체적인 행동을 취해야 할 때인 바, 2 위 원회가 정상들의 공약을 행동으로 전환시키는 결 의안을 채택함으로써 이러한 노력에 기여할 수 있 기를 희망함.

$\square$ 개도국들이 개발에 관한 ownership을 재확인한 것을 환영함. 우리의 경험에 비추어 볼 때 다방면 에 걸친 국가개발전략과 개혁은 가용한 개발재원 을 증대시키고 이를 더욱 효과적으로 사용케 하는
바, 개도국들이 자신들의 공약을 달성하기 위해 최선의 노력을 다할 것을 희망함.

- 아울러, 많은 선진국들이 2015년까지 GNI의 $0.7 \% \mathrm{ODA}$ 목표 달성을 위한 시간표를 제시하 고 여타 선진국들도 ODA 를 실질적으로 증가시 키기로 한 것은 고무적임.

$\square$ 한국은 1997년 아시아 금융 위기에도 불구하고 2000 04년간 ODA 를 배증하였으며, 2009년까 지 이를 다시 배증하기 위해 노력할 것임. 아울러 한국은 ICT에 관한 우리의 자원과 전문성을 활용 하여 ESCAP과의 협력하에 최초 설립비용으로 1 천만불을 투자, APCICT 를 한국에 설립할 예정임.

$\square$ 장기 개발 재원 마련을 위해서는 ODA 만으로는 충분치 않은 바, 경제성장을 위한 동력으로서 무 역의 역할이 강화되어야 할 것임. 이러한 맥락에 서 홍콩 WTO 각료회의에서 도하개발계획 이상의 성과를 거두기를 희망함.

$\square$ 한국은 개발의 필수적인 요소로서 선정과 부패 척 결을 위해 노력하고 있음. 우리는 조만간 반부패 협약을 비준할 준비가 되어 있는 바, 아직 동 협약 에 서명하지 않은 국가들은 이를 서명, 비준, 이행 하기를 바람. 아울러 우리는 제6차 정부혁신세계 포럼의 후속조치로서 유엔 거버넌스 센터를 한국 에 설립하기 위해 유엔 사무국과 협력하고 있음.

$\square$ 보건 분야 관련, 한국은 AIDS, 말라리아 및 결핵 퇴치 기금에 기여하고 있으며, 국제백신연구소 활 동 지원 및 조류 독감 및 광역전염병에 관한 국제 파트너십을 출범시키는 데 참여해 오고 있음.

$\square$ 한국은 NEPAD, 브뤼셀 행동 계획, 알마티 행동 
계획, 바베이도스 행동 계획 및 모리셔스 전략을 지원해 오고 있으며, 이러한 노력을 계속해 나갈 것임. 아울러 국제사회가 세계 빈국의 $2 / 3$ 와 최빈 국 인구의 $40 \%$ 가 있는 이태 지역에 대한 지원에 주의를 계속 기울이기를 바람.

$\square$ 금번 정상회의에서 지속가능개발을 위한 정상들의 의지가 재확인되었는 바, 이를 계기로 구체적인 결 과 달성을 위한 효과적인 방안이 마련되도록 노력 해 나가야 할 것임. 우리는 차기 CSD가 에너지, 기 후, 공해 및 산업에 관한 더욱 통합된 정책 대안을 마련할 수 있기를 기대하며, 차기 UNFCCC 당사 국 회의가 온실가스를 줄일 수 있는 즉각적이고 효 과적인 결과를 도출할 수 있기를 희망함.

\section{2. 북한 발언요지}

$\square \mathrm{MDGs}$ 달성을 위해서는 빈곤 퇴치 및 개발에 호의 적인 조건 및 상황을 만드는 것이 긴요함. 그러나 불공정한 국제경제 질서가 있는 한 그러한 환경을 조성하고 선. 후진국간 격차를 줄일 수 없음.

- 현존하는 국제경제질서하에서는 개발에 관한 개 도국의 권리는 무시되고 개도국의 의사와 요구는 개발정책 수립 과정에서 존중되지 못하고 있음.

$\square$ 우리는 개도국의 주권과 개발권을 위협하는 비합 리적인 전제조건과 군사적 공격, 경제제재 및 봉 쇄와 같은 고압적인 조치들이 인도주의, 인권 옹 호 및 빈테러리즘이라는 미명하게 묵인되고 정당 화되는 것을 간과해서는 안될 것임.

$\square$ 선진국은 전제 조건없는 직접 투자는 물론 ODA 를 증가시키고 외채 해결을 위한 단호한 의지를
보여주어야 할 것임.

$\square$ 다자 무역 및 국제금융체제는 개도국의 동등하고 완전한 참여를 보장하고, 개도국에 대한 특혜 조 치 및 개발자금을 증가시키는 방향으로 개혁되어 야 할 것임.

- 국제개발정책은 개도국의 경제 자급 능력을 향 상시킬 수 있도록 개도국의 국가개발정책을 지 원하여야 할 것임. 국가마다 다른 경제개발능력 을 고려할 때 모든 국가에 적용되는 보편적이고 특정화된 경제 모델은 있을 수 없음.

$\square$ 무제한적인 시장자유경쟁, 경제제재 및 봉쇄, 개 도국에 대한 고압적인 조치는 개도국의 주권을 침 해하며 개도국의 경제 사회 발전에 악영향을 미 침. 북한은 유엔 헌장에 반하는 일방적이고 치외 법권적이며 고압적인 경제조치는 어떠한 경우에 도 허용되어서는 안되며 정당화되어서는 안된다 는 것을 촉구함.

$\square$ 북한은 외부세력에 의해 초래된 군사적 긴장과 경 제적 어려움 가운데 인민 생활의 안정과 경제재생 에 중점을 두어 경제 구조를 개혁하고 완전하게 해 옴. 아울러 지속가능개발을 위해 대규모 농지 재정리 및 수로 건설, 에너지 문제를 해결하기 위 한 중 소규모 수력 발전소 건설 등을 통해 국가 경제의 자립적 기초를 강화하는 조치 등 새로운 경제 조치들을 취하고 있음.

$\square$ 북한은 향후 MDGs 달성을 위해 국제사회와의 협 력적인 관계를 더욱 발전. 향상시켜 나갈 것임.

[자료 : 주국제연합 대표부] 